\title{
A TEORIA CONTEMPORÂNEA DO CINEMA
}

\author{
José Carlos Felix ${ }^{1}$
}

\begin{abstract}
Resumo: O presente ensaio pretende discutir as vicissitudes da teoria contemporânea do cinema diante do fenômeno pós-estruturalista conhecido como Teoria. Para isso, partimos de uma problematização das grandes correntes que moldaram o pensamento teórico sobre o cinema ao longo do século XX e cujas temáticas refletem as duas correntes de pensamento que vem dominando o debate e a produção dos escritos sobre cinema após 1970: a teoria de posição subjetiva e culturalismo. Em relação à primeira vertente, os ensaios "Prazer visual e cinema narrativo" (1975) e "Reflexões sobre "Prazer visual e cinema narrativo' inspiradas por Duelo ao sol, de King Vidor" (1981) de Laura Mulvey serão tomados como base para uma reflexão dessa questão. Já na última seção, o ensaio O "A alegoria histórica", de Ismail Xavier, e o livro Crítica da imagem eurocêntrica(1994), dos críticos norte-americanos Robert Stam e Ella Shohat nos permitirão problematizar a questão das representações culturais e políticas do cinema - especialmente o não eurocêntrico - a partir de uma concepção multiculturalista.
\end{abstract}

Palavras-chave: Teoria contemporânea do cinema. Pós-estruturalismo. Teoria de posição subjetiva. Multiculturalismo.

\section{THE CONTEMPORARY THEORY OF CINEMA}

\begin{abstract}
This essay aims at discussing the vicissitudes of cinema's contemporary theory amidst the poststructuralist phenomenon known as Grand Theory. In this sense, we first introduce a panoramic discussion concerning the major trends that shaped the theoretical thought regarding cinema throughout the XX century and which issues reflected two trends that established the debate on the cinematic field after 1970 onwards: the theory of subjective position and multiculturalism. With regards to the first trend, the essays "Visual pleasure and narrative cinema" (1975) and "Afterthoughts on 'Visual pleasure and narrative cinema' inspired by Duel in the Sun (1981), both by Laura Mulvey, will be taken as a starting point for a discussion on the theory of subjective position. By the same token, the essay “A alegoria histórica”, by Ismail Xavier and Unthinking Eurocentrism: Multiculturalism and the Media, by Robert Stam and Ella Shohat, will allow us to reflect the issue of cultural and political representation on cinema - especially non-Eurocentric - from the viewpoint of multiculturalism.
\end{abstract}

Keywords: Contemporary theory of cinema. Poststructuralism. Theory of subjective position. Multiculturalism.

\footnotetext{
${ }^{1}$ Doutor em Teoria e História Literária pela Universidade Estadual de Campinas (UNICAMP). Pesquisador pelo grupo Pós-Teoria, UNEB/Pós-Crítica. Endereço eletrônico: jcfelixjuranda@yahoo.com.br.
} 
José Carlos Felix

\section{Introdução}

A recente a coletânea Teoria Contemporânea do Cinema (2005), organizada por Fernão Ramos, distingue-se particularmente das demais publicações do gênero disponíveis no mercado editorial brasileiro, notório tanto pelo limitado número de títulos sobre o assunto quanto pelos dois formatos típicos de sua apresentação: antologias das principais obras do pensamento teórico fundador desse campo e extensos panoramas explicativos acerca de seu desenvolvimento ao longo de seu primeiro século de existência. Como exemplo dessa última categoria, dois livros em particular se destacam: a volumosa, mas igualmente lacônia Introdução à teoria do cinema (2006), do crítico norte-americano Roberto Stam, listando em seu índice nada menos que quarenta e duas abordagens e movimentos teóricos sobre cinema, mas que de fato não chega a dispensar mais que dez páginas para cada uma, evidenciando assim um estilo raso de escrita pós-moderna, caracterizado por uma enumeração infindável de tendências, mas destituída de qualquer intencionalidade em promover uma discussão de profundidade; o segundo trata-se do relançamento da tradução para o português de As principais teorias do cinema $^{2}$ (2002), do renomado crítico e professor de cinema da universidade de Yale, J. Dudley Andrew, que, apesar de fornecer um minucioso e detalhado estudo das obras e teóricos que moldaram as duas principais tradições dos estudos de cinema na primeira metade do século passado, resvala num anacronismo, ao destacar a semiologia do cinema de Christian $\mathrm{Metz}^{3}$, como o grande expoente da teoria francesa contemporânea. Por sua vez, no que tange ao gênero antologia, $A$ experiência do cinema (1983), organizada pelo também crítico brasileiro e professor de cinema, Ismail Xavier, permanece ainda como uma importante referência sobre teorias da imagem e uma das completas compilações sobre o assunto lançadas no Brasil.

\footnotetext{
${ }^{2}$ Publicado em 1976, o livro apresenta um recorte temporal bastante determinado, ao concentrar-se na exposição das duas principais tradições teóricas que dominaram o pensamento sobre cinema até meados de 1960. A primeira tradução para o português, de 1989, encontrava-se esgotada há alguns anos.

${ }^{3}$ Em termos de movimentos e tendências, a semiologia fílmica desenvolvida por Metz, ilustrada nos livros A significação no cinema (1968) e Linguagem e cinema (1971), refletiu as influências do estruturalismo nos estudos fílmicos que, nos Estados Unidos, apesar do pouco impacto e curta duração, marcou a transição das duas primeiras grandes tradições teóricas (Formativa e Realista) para o pós-estruturalismo (cf. BORDWELL, 2005, p. 25-9).
} 
Um exame mais detido dessas obras demonstra, no entanto, que além de estarem voltadas majoritariamente às questões da evolução tecnológica, destacando pontos de confluência de gêneros e suportes, tais títulos apenas subscrevem as duas linhas centrais que assinalaram o debate sobre cinema ao longo de suas primeiras cinco décadas: seja no esforço em cunhar uma tradição formativa e de orientação mais formal, circunscrita a um conjunto de bases conceituais próprias, pautadas nas especificidades dos códigos fílmico, tencionando, sobretudo, conferir-lhe o status de uma nova forma de arte, e que marcou os trabalhos de toda uma geração de pioneiros como Eisentein, Balázs, Arnheim e Munsterberg; ou ainda, na elaboração de uma formulação teórica, denominada realista, que concebia o cinema como uma potência política e cultural capaz de provocar transformações significativas na experiência social erigida no bojo da mercantilização, estruturadora da moderna sociedade de massas, sobre as quais os escritos de Kracauer e Bazin ${ }^{4}$ se voltaram.

Contudo, mais do que suprir uma lacuna nesse tipo de publicação, disponibilizando o acesso a um conjunto de significativos escritos que compõe a chamada "teoria contemporânea do cinema", a coletânea organizada por Ramos permite, sobretudo, a possibilidade de examinar de modo mais detido as profundas transformações ocorridas nesse campo em particular nas três últimas décadas. O recorte temporal, todavia, não é sem propósito, pois os ensaios e textos contidos nessa coletânea circunscrevem-se dentro de um marco de fundamental relevância no universo acadêmico, em particular, no contexto acadêmico norte-americano: a emergência da Teoria. Diferentemente, das teorizações produzidas tanto pela tradição formativa quanto realista, a teoria contemporânea do cinema assinala um duplo e paradoxal movimento nesse campo: se por de um lado, caracteriza-se como o momento em que os estudos de cinema firmam-se enquanto disciplina acadêmica e conquistam assim o almejado status de campo, por outro lado, essa outorga não se deu sem um rompimento com as tradições que conferiam suas especificidades técnicas e formais, para fundir-se e desaparecer em uma

\footnotetext{
${ }^{4}$ Para uma leitura pormenorizada de ambas as tradições, ver Andrew (2002), Stam (2006), Xavier (2003). Já os ensaios que compõem $A$ forma do filme, de Eisenstein (1990), mostram a importância dessa obra como um marco na teorização do cinema e seu empenho em encontrar nos aspectos formais filme uma autonomia enquanto arte. Para tradição realista, Cinema como prática social, Turner (1997) oferece uma elucidativa discussão sobre o assunto.
} 
amálgama de tendências e aparatos explicativos, cujo objetivo era utilizar filmes como índices que permitissem uma reflexão sobre amplos aspectos da sociedade e da subjetividade.

Como esse texto procurará demonstrar, o principal traço distintivo entre as duas primeiras grandes tradições teóricas sobre o cinema e a produção das últimas décadas encontra-se na mudança pólos entre ambas; isto é, enquanto as primeiras distinguem-se, sobretudo, pelo esforço em demarcar especificidades e os aspectos formais constitutivos do cinema, essa última advoga irrevocavelmente pela pluralidade e diversidade do pensamento, centralidade temática, além de toda sorte de agendas. Um indicativo desse "caráter plural" vociferado pelos estudos contemporâneos sobre cinema encontra-se já nas primeiras linhas da introdução de Ramos para a seleta, onde o organizador enfatiza que o objetivo central da antologia é "refletir a diversidade do pensamento em cinema hoje", deixando de lado as especificidades constitutivas do campo cinematográfico, para expor a "riqueza dos conceitos do pensamento que nele se inspirou" (2005, p. 11).

No que tange à compilação dos textos, não há dúvidas acerca do ecletismo que ordena os dois volumes, composto dos seguintes grandes temas: 1 - "Cognitivismo e filosofia analítica" e 2 - "Pós-estruturalismo"; os dois grandes capítulos do primeiro volume; 3 - "Cinema documentário" e 4 "Narratividade e estilística cinematográfica”, formam o segundo. Todavia, há nessa divisão um intrigante aspecto na ordem distributiva dos textos para cada seção. Enquanto os capítulos 1, 3 e 4 possuem uma média de quatro a seis textos cada, salta aos olhos o tamanho do capítulo 2 (pós-estruturalismo), cujos textos encontram-se agrupados em quatro subseções, assim intituladas e com os seguintes títulos: a) Textos gerais - "O acinema” de Lyotard; "Pensar, contar: o cinema de Gilles Deleuze” de Bellour; "Deleuze e as virtualidades da narrativa cinematográfica" de Patente; b) Subjetividade e questão autoral - "Idéias de autoria" de Buscombe; “Comentário sobre idéia de autoria” de Heath; "Crítica ao cinema estruturalismo" de Henderson; c) Suture (Sutura) "O código tutor do cinema clássico" de Dayan; d) Estudos culturais “A alegoria histórica” de Ismail Xavier; "Reflexões sobre Prazer visual e cinema narrativo inspiradas por Duelo ao sol, de King Vidor (1946) de Laura Mulvey"; Teoria do cinema e 
espectatorialidade na era dos "pós" de Robert Stam e Ella Shohat. Feitas as contas, não há dúvidas que ênfase e amplitude conferida a esse segundo exatamente a mesma quantidade de textos (dez) que compõem os dois capítulos do segundo volume - salientam a proeminência dada ao recorte denominado "pós-estruturalista" e cujas temáticas refletem as duas correntes de pensamento que vem dominando o debate e a produção dos escritos sobre cinema após 1970: a teoria de posição subjetiva e culturalismo 5 .

Conspícuo também é o fato de que os temas dos textos que constituem o capítulo extenso refletem a propalada pluralidade constitutiva dessas duas correntes nas formas de discussão sobre gênero (feministas), minorias (sexuais e raciais), apagamento das fronteiras entre o cinema e as demais formas de arte e mídias; todas revestidas por um notório anseio em definir-se como politicamente progressista. Logo, "diversidade", aqui, apresenta-se como o grande tema aglutinador de todos os textos do capítulo, e não uma categoria diferenciadora entre eles.

Feitas tais considerações, é justamente sobre essa configuração, notadamente informada pelo surgimento e consolidação da Teoria como base epistemológica, que pretendo discorrer nas páginas seguintes. Parto do exame de três textos em particular da seção de "estudos culturais", os quais apresentam como salutares pontos de partida tanto para uma caracterização quanto reflexão acerca das questões (e decorrentes problemas) das correntes denominadas teoria de posição-subjetiva e culturalismo. Tencionando tornar a reflexão mais elucidativa, também abordarei outros ensaios, textos e livros que abarcam a mesma questão.

\section{Do filme ao sujeito: princípios da teoria de posição-subjetiva}

Os conhecidos textos "Prazer visual e cinema narrativo"6 (1975) e “Reflexões sobre ‘Prazer visual e cinema narrativo' inspiradas por Duelo ao sol,

\footnotetext{
${ }^{5} \mathrm{O}$ marco temporal é tão forte que, ao referirem-se de forma genérica às essas duas tendências, críticos como Bordwell (p. 44), Allen \& Smith (p. 83), Stam (p. 186) denominam-na apenas de "teoria de 1975". De acordo com Stam, a divisa refere-se ao lançamento do periódico francês Communications, dedicado à "Psicanálise e o Cinema", inaugurando assim uma tendência na qual o debate sobre cinema passaria a apresentar uma inflexão psicanalítica.

${ }^{6}$ Uso aqui a versão em português do texto, publicada em Ismail Xavier (Org.). A experiência do cinema (2003), p. 437-453.
} 
de King Vidor" (1981) de Laura Mulvey, apresentam-se, sem dúvidas, como profícuos pontos de partida para uma caracterização e crítica do paradigma dominante na teoria do cinema de orientação semiótico-psicanalítica, sendo a interação entre essas duas áreas a espinha dorsal da teoria de posiçãosubjetiva. Publicado em 1975, na revista Screen, "Prazer visual..." revela a explícita e estreita vinculação das posições teóricas advogadas por Mulvey com o cinema alternativo, tencionado estabelecer as fundações para uma proposta efetiva de realização de um cinema de orientação política e anti-sistema, engendrando transformações na linguagem e na estética fílmica capazes de romper o "contrato de assistência" instituído entre o cinema dominante (o cinema clássico de Hollywood) e o espectador. Tal proposição justificaria-se pelo o fato de que padronização de códigos narrativos desenvolvidos pelo sistema da indústria cinematográfica, entre outras coisas, “codificou o erótico dentro da linguagem de ordem patriarcal dominante” (p. 440). Para a crítica, foi justamente o estabelecimento dos códigos do cinema dominante que o sujeito alienado, amputado em sua memória imaginativa por um potencial sentido de perda, consegue recobrar, na beleza formal desse cinema, um pouco do seu prazer e do "jogo com as suas próprias obsessões formativas" (p. 440). No horizonte dos problemas tratados por Mulvey, a psicanálise desponta como um instrumento essencial para uma reflexão acerca do prazer específico vinculado a uma experiência cinematográfica dominante e, ao mesmo tempo, pensar em formas de balizamento e transformação da extirpação desse prazer em uma forma de resistência e arma de luta, criando uma outra linguagem cinematográfica (p. 439-40).

Nesse sentido, Mulvey apresenta uma teorização sobre cinema articulando fundamentos da psicanálise (a escopofilia) aos ideários do feminismo (patriarcado) para explicar como o cinema dominante mobiliza três formas de olhar: o da câmera, o das personagens olhando-se mutuamente e do espectador, induzido a olhar voyeuristicamente com o olhar masculino sobre a mulher. Nessas formas de escopofilia engendradas pelo cinema clássico, circunscrevem-se, para ela, as marcas do falocentrismo estruturador das convenções da sociedade patriarcal, revigorando a figura da mulher como um objeto subordinado tanto em nas formas de estruturação narrativa quanto de espetacularização. A postulação teórica sobre a narrativa fílmica que institui o 
masculino como sujeito ativo e o feminino em objeto passivo de olhar espectatorial marcadamente masculino, inscreve-se na noção lacaniana de que o desejo não é uma questão de desejar o outro, mas, de "desejar o desejo do outro" que, para Stam, teve um grande apelo para explicar o processo de identificação no cinema e estruturou grande parte de teoria de posiçãosubjetiva (2006, p. 186). Logo, o caminho tomado por Mulvey, e por muitos outros que seguiriam essa corrente ${ }^{7}$, retoma as noções psicanalíticas de conceitos como voyeurismo, fetichismo e narcisismo para explorar, sob uma nova perspectiva, a dimensão metapsicológica do cinema, através dos seus mecanismos de ativação e regulação do desejo do espectador, apontados por Metz em The imaginary signifier(1982, p. 51).

Vale ressaltar que, apesar dos problemas contidos nessa perspectiva teórica a serem discutidos mais adiante, a elaboração de um aparato de interpretativo que encadeie em uma única conjunção campos distintos como a semiologia, a psicanálise e o feminismo - só para ficar no caso do ensaio em questão -, expõe, ao mesmo tempo, o empenho dos trabalhos da corrente da teoria de posição-subjetiva em estabelecer uma ruptura com as tradicionais abordagens psicológicas que dominaram aos estudos literários no final do século XIX e início do século XX. Isto é, a aplicação de preceitos psicanalíticos para investigar a psique do autor ou dos personagens.

Por outro lado, não é que, três décadas após sua publicação, a argumentação de que, no cinema clássico, o prazer visual encerra-se em uma categoria estrutural rígida, fundada numa noção de gênero, onde o masculino objetifica o feminino através do olhar, reencenando uma estruturação social binária que reflete as assimetrias das relações de poder em vigor no mundo social real, soe incontestavelmente anacrônico. Mesmo assim, permanece notável a habilidade com que Mulvey encadeia os vários aspectos acerca do prazer visual e compõe com o vigor de seu raciocínio argumentativo. Neste ponto, destaca-se a solução encontrada para resolver a tensão entre as forças opostas do voyeurismo e do processo de identificação, encapsulado no papel

7Ver "A psicologia da experiência cinematográfica" (1949); de Hugo Mauerhofer, "Discurso/história (nota sobre dois voyeurismos)" (1975), de Christian Metz; "Dispositivo cinematográfico como institutição" (1979), de Christian Metz; “A voz no cinema: a articulação de corpo e espaço” (1980), de Mary Ann Doane (1080). 
ambivalente da figura feminina que, ao mesmo tempo em configura-se como objeto instigador do desejo, seja do protagonista masculino ou ainda da identificação do espectador com este, mantém em si a essência fundadora do “complexo da castração”. A saída para esse desacordo, segundo ela, encontrase numa forma de escopofilia fetichista capaz de elaborar e potencializar a "beleza física do objeto, transformando-o em alguma coisa agradável em si mesma" e, consequentemente, destituída de qualquer risco ou ameaça ${ }^{8}(2003$, p. 447). Destarte, a imagem feminina, ou qualquer fragmento dela, tornaria-se inequivocamente um ponto atrativo do olhar e, dada sua existência "fora de um tempo linear", configuraria-se como uma instância autônoma e desvinculada a qualquer inserção narrativa (2003, p. 447).

Obviamente, uma formulação que se propõe discutir a condição inequívoca a passividade feminina a partir do referencial psicanalítico, acentuado, sobretudo, em sua identificação masoquista com protagonista masculino do cinema clássico, certamente não passaria incólume diante da crítica; especialmente a feminista. Várias foram às objeções ao trabalho de Mulvey: Glendhill contestou a insistência na abordagem semiótica característica desse feminismo cinematográfico, pois uma moldura teórica que confira o feminino uma posição de objeto e ainda subscreve como forma de identificação única o protagonista do melodrama subtraia qualquer possibilidade de resistência à ideologia contida nos atores sociais (1987, p. 138); ou ainda, como argumentou Rodowick (1991), desconsiderava o espaço para variabilidade histórica (p. 72); já Cowie (1997) contra-argumenta com uma série de exemplos de filmes em que identificação oscila em grau entre diferentes personagens (masculinos e femininos), e assim escapavam a uma formulação binária de gêneros; Stam menciona ainda uma edição especial da revista Câmera Obscura (1989) que enumerou cerca de cinquenta respostas ao ensaio e dirigiam a maior parte da crítica ao caráter determinista, redutor e indiferente da formulação e que, segundo ele, desconsiderava as inúmeras maneiras pelas quais o olhar masculino é subvertido, redirecionado e sabotado pelas mulheres (STAM, 2006, p. 197).

\footnotetext{
${ }^{8}$ Esse abrandamento e extirpação do "complexo da castração" na figura feminina seria uma possível explicação tanto para supervalorização quanto para o culto da star feminina.
} 
A própria Mulvey reconheceu prontamente as limitações e problemas nessa visão da espectadora feminina e assim em, "Reflexões sobre 'Prazer visual e cinema narrativo'”, faz uma autocrítica sobre esse fatalismo e tenta superá-lo na elaboração de dois outros conceitos, oscilação e travestimento, sem abrir mão, contudo, das influências psicanalíticas, há muito já abandonadas e severamente criticadas pelas feministas (cf. GLENDHILL, 1997). Mesmo assim, “Reflexões..." recorre novamente a Freud na tentativa de diluir a rigidez das categorias binárias de masculino/ativo e feminino/passivo. Citando Freud, a autora parte do postulado de que "muito frequentemente ocorrem regressões às fixações das fases pré-edipianas; no transcorrer da vida de algumas mulheres, existe uma repetida alternância entre períodos em que ora a masculinidade, ora a feminilidade, predominam" (FREUD apud MULVEY et al. 1964), para, em seguida, afirmar que essa oscilação característica descrita por Freud, e que envolve procedimentos ativos de identificação, é parte constitutiva da formação da feminilidade. A fim de demonstrar a estruturação dessa função cambiante da mulher, Mulvey articula então três elementos - o conceito de Freud sobre a "masculinidade" nas mulheres (acima citado); a identificação desencadeada pela lógica de uma gramática narrativa (argumento de seu ensaio anterior); e o desejo do ego em travestir-se de uma forma ativa (p. 386) - e os exemplifica a partir da tríade de personagens do western Duelo ao sol[Duel in the sun] (1946), de King Vidor. Seu argumento intenta demonstrar como a introdução de uma personagem feminina como elemento central da narrativa, mesmo em um gênero notadamente misógino e celebre por reforçar estereótipos da figura feminina como objeto, por exemplo, gera mudanças substanciais em seus significados, “produzindo um outro tipo de discurso narrativo" (p. 388).

Na trama, dois personagens masculinos, Jesse e Lewt, disputam a atenção da personagem Pearl. Embora os dois protagonistas reencenem o clássico duelo entre herói e vilão, fundamental a esse gênero, a posição antagônica de um e outro, nesse caso, serve a uma outra função: ambos são objetos de identificação (ativo e passivo) para Pearl. Logo, Jesse, com seus

${ }^{9}$ Título original "Afterthoughts on 'Visual Pleasure and Narrative Cinema' inspired by King Vidor's Duel in the Sun (1946)", em Laura Mulvey, Visual and Other Pleasures (Bloomington: Indiana University Press, 1989), p. 29-38. Uso aqui a tradução de Silvana Viera (ver referência). 
"livros, terno escuro, formação jurídica, gosto pela erudição e pela cultura, dinheiro, etc", representa o estatuto correto da ordem social apassivadora a ser seguida por uma mulher para tornar-se uma “dama”, enquanto Lewt, envolto com suas "armas, cavalos, desrespeito às leis e a ordem social”, oferece a Pearl (e, consequentemente, para as espectadoras) a possibilidade de identificação com um objeto de dimensões transgressoras. Mesmo que, no final da trama, Pearl descubra que também há tão pouco espaço para si no mundo truculento e misógino de Lewt quanto para a realização de seus desejos como esposa de Jesse, como Mulvey reconhece ao final de sua leitura. Contudo, o mais importante para a autora aqui é poder revisar e superar as limitações do molde produzido no primeiro ensaio, demonstrando que a série de oscilações entre as duas identificações de Pearl assinala a possibilidade para uma forma de resistência na qual "o poder da masculinidade pode ser usado como um adiamento contra o poder patriarcal” (p. 391).

O reconhecimento de Mulvey de que as formas narrativas do cinema clássico podem também oferecer outras formas menos rígidas de identificação, certamente arrefece o tom radical do argumento de seu primeiro ensaio, no qual asseverava que somente uma produção cinematográfica alternativa, livre de práticas ideológicas ${ }^{10}$, impediria tais identificações dominantes, ao mesmo tempo em que abririam o leque de formas de identificação alternativas. Todavia, se por um lado, o cotejo dos dois ensaios fornece a possibilidade de uma visualização e, até certo ponto, do desenvolvimento de seus argumentos, por outro, tanto sua elaboração teórica quanto a aplicação que faz dela nos filmes que interpreta, nos oferece um material interessante para pensarmos a peculiar função que cinema desempenhou nos escritos arrolados na teoria de posição-subjetiva.

Uma rápida descrição da estruturação dos dois ensaios fornece subsídios suficientes para entendermos essa questão: em ambos, salta aos olhos a preocupação de Mulvey em recapitular e explicar, de maneira excessivamente esquemática, conceitos psicanalíticos e o encadeamento

\footnotetext{
${ }^{10}$ Em Women's Pictures: Feminism and Cinema, um livro extremamente panfletário do ideário feminista das décadas de 1960-70, Annette Kuhn vocifera contra o caráter altamente ideológico do cinema dominante que, para ela, de seus códigos narrativos e processos enunciativos, era responsável por construir posições subjetivas definidas por e a serviço de uma ideologia dominante (1982, p. 47-9).
} 
desses com os códigos e aparatos do cinema dominante, tencionando expor a maneira como, no bojo da imbricada relação entre ambos, opera o prazer visual. Como já observado, a autora expõe seu argumento e articula questões de ordem diversa surpreendente domínio. A questão que nos chama atenção está, contudo, em seu tratamento dos filmes, ou melhor, na forma como os utiliza. Nos dois casos, tanto a escolha dos filmes quanto a abordagem utilizada, estes cumprem exclusivamente o papel de elucidar as proposições argumentativas construídas ao longo dos textos; enquanto objetos de uma atividade interpretativa, nesses ensaios, os filmes tem compromisso apenas de comprovarem uma posição teórica. Além disso, o encolhimento da posição do objeto, nesse caso, é também indicativo de que, juntamente com o anseio por aplicabilidade teórica, a teoria de posição-subjetiva inscreve os estudos de cinema no célebre deslocamento do foco de interesse pela obra, já transformada em Texto, para a entidade de leitor, arrolada na miríade de formulações teóricas do pós-estruturalismo.

Dessa forma, no final de "Prazer visual e cinema narrativo", filmes dos diretores Hitchcock e Sternberg são tomados para explicitar os dois esquemas em funcionamento de uma ordem simbólica caracterizadora da figura feminina como objeto (p. 448-51). Em uma sintética explanação, destituída de qualquer preocupação em examinar pormenorizadamente a maneira como os aspectos formais dos filmes desses cineastas contribuem para a comprovação de sua tese, Mulvey, não avança muito além da enumeração de alguns títulos de filmes para comprovar que enquanto Hitchcock (o mais complexo, segundo ela) caminha em direção à investigação do voyeurismo, os filmes de Sternberg "fornecem exemplos de pura escopofilia pura" (p. 448). Ademais, embora sua tese sobre o "prazer visual" seja estreitamente fundada na crítica ao cinema clássico, a autora não faz nenhuma menção de como recursos técnicos como a manipulação encadeada na continuidade de edição, ou como os elementos do sistema de estruturação narrativa, por exemplo, opera sobre o espectador, incitando o voyeurismo. Compreendido por dois elementos - a estrutura da história clássica resultante das motivações psicológicas dos personagens e sistema fílmico de tempo - o sistema de estruturação narrativa manipula a trama de modo específico e, juntamente como o sistema de tempo, ambos entrelaçam-se em uma ordem 
hierárquica onde estrutura da narrativa determina tempo e espaço ${ }^{11}$. Embora esses códigos e convenções estilísticas do cinema clássico resultem em uma série de restrições para a expressão individual num cinema mais autoral e alternativo, justamente como critica Mulvey, esses recursos são sempre rearranjados em combinações determinadas pelo tipo de efeitos que a função narrativa pretende provocar no espectador. Logo, a demonstração do modus operandi dessas funções seria extremamente para entender a operação do voyeurismo e identificação, não como um esquema teórico a parte, mas em funcionamento nos filmes dos diretores citados.

O caso de "Reflexões sobre o 'Prazer"' reforça ainda mais essa hipótese, posto que, nesse ensaio, a estratégia de abordagem dos filmes permanece. Nele, tem-se uma breve exposição das personificações edipianas no gênero western tomando como exemplo $O$ homem que matou facínora (1962); a estrutura rígida de dois personagens centrais antagonistas caracteriza, para a autora, um sintomático de narrativa fílmica em que o homem é o condutor do veículo narrativo, não havendo, portanto, espaço para a mulher que não seja o de objeto de escopofilia. A abordagem serve exclusivamente a dois claros propósitos: elucidar os conceitos psicanalíticos já expostos; servir de contraponto à exposição seguinte de como as possibilidades de leitura, e identificação, são alteradas quando uma figura feminina passa ocupar uma posição de centralidade, como discutido acima. Nesse caso em particular o desinteresse por elementos formais do filme é ainda mais conspícuo, e contradição argumentativa ainda maior. Valendo-se do conceito de função do personagem baseado em Morfologia do conto maravilhoso, Mulvey afirma que o gênero western "traz uma impressão residual da primitiva estrutura narrativa de analisada por Propp nos contos populares", além de também apresentar "laços estreitos com as observações de Freud sobre o devaneio" (p. 386). As explicações param por aí, no entanto, não qualquer referência pormenorizada sobre os que são essas postulações teóricas da teoria literária e da psicanálise ou sobre como esse encadeamento opera na narrativa fílmica do gênero western. Este, por sua vez, também não recebe a mínima delimitação conceitual.

\footnotetext{
${ }^{11}$ Ver Bordwell, D., Staiger, J., Thompson, K. The classical Hollywood Cinema (1985).
} 
Vale observar, todavia, que, alguns escritos dessa corrente inscrevem um novo estatuto ao que vem a ser a forma do filme assim com sua função. O tratamento das questões formais desloca-se dos elementos intrínsecos do filme ${ }^{12}$ para uma formulação de bases psicanalíticas tencionada em investigar os dispositivos cinematográficos como uma máquina tecnológica, institucional e, sobretudo, ideológica com profundos efeitos na identificação espectatorial. O ensaio "Cinema: efeitos ideológicos produzidos pelo aparelho de base" (1970) ${ }^{13}$, de Jean-Louis Baudry, aparece como um sintomático exemplo dessa tendência, denominada posteriormente "teoria do dispositivo". Nele, Baudry parte de uma consideração ampla acerca da falsa neutralidade dos aparelhos óticos para discutir questões como participação afetiva, o jogo das identificações e constituição do espectador como sujeito. Essas questões são articuladas a partir de uma esquematização que aproxima referenciais lacanianos (fase do espelho) e althusserianos (os aparelhos ideológicos) a fim de examinar o chamado "aparelho de base" do cinema: o sistema integrado câmera/imagem/montagem/projeto/sala escura. Em linhas gerais, a descrição Baudry acerca dessa maquinaria em operação revela, para ele, a existência de um "substrato inconsciente" profundo na identificação do espectador com as imagens projetadas na tela ${ }^{14}$ (p. 385). Logo, a sessão de cinema, como seu dispositivo de simulação, produz uma espécie de regressão análoga ao conceito lacaniano de "fase do espelho", entendida como a matriz originária das experiências de identificação e na qual a criança pensa reconhecer a si mesma no espelho, iniciando um processo de definição do seu ego narcisisticamente como um corpo unificado e visível. O autor argumenta que, essa reativação do "efeito-sujeito", recriada pelos aparatos cinematográficos, que caracteriza como aparelho psíquico substitutivo com o qual nos identificamos com prazer; conclui-se assim que o cinema "aparece como uma espécie de aparelho psíquico substitutivo, respondendo ao modelo definido pela ideologia dominante" (p. 385). Vale ressaltar que, dado seu interesse em discutir e apontar como o caráter essencialmente ideológico engendrado na experiência cinematográfica, Baudry parece muito mais empenhado em explicar os

\footnotetext{
${ }^{12}$ São eles: campo/contracampo, plano sequência, profundidade de campo, espaço/som fora de campo, montagem paralela, raccord, falso raccord, primeiro plano, entre outros.

${ }^{13} \mathrm{Em}$ A experiência do cinema, Ismail Xavier (Org.). p. 383-399.

${ }^{14}$ Baudry vale-se até um gráfico para explicar esse funcionamento (p. 385).
} 
complexos mecanismos do aparelho psíquico da base lacaniana do que os aparatos fílmicos. Assim como a utilização dos filmes por Mulvey, eles servem como uma grande tela na qual uma elaborada formulação teórica pode ser projetada com fins demonstrativos.

Os ensaios discutidos acima, ambos pioneiros e influentes, nos permitem apontar com mais consistência ao menos duas características que compõe a teoria de posição-subjetiva de forma geral, a saber: a preocupação em investigar as funções psíquicas e ideológicas do cinema; a noção de sujeito como categoria de conhecimento, definida em sua relação de identificação com os objetos e com os outros. Aliás, a ideia de que indivíduo é construído como sujeito epistemica e socialmente é argumento central tanto para teoria de posição-subjetiva quanto para o culturalismo, que veremos a seguir, pois descreve uma configuração identitária adequada a um sistema social estruturado em papeis - trabalhador, patrão, intelectual -, com posições definidas na relação das lutas de classe. A estruturação social patriarcal elaborada no feminismo psicanalítico dos textos de Mulvey seria apenas uma variação de gênero sobre essa mesma moldura.

De modo geral, chama a atenção, contudo, que as críticas a essa corrente foram de ordem bem mais pragmática. Bordwell (2005) observa que a objeção mais recorrente centrou-se num certo tipo de fatalismo e inércia nessas esquematizações que não conferiam muito espaço nem propunham alternativas para se pensar em resistência por parte dos "atores sociais" contra as formas dominantes de representação, como o cinema clássico de Hollywood (p. 34). A crítica mais recente e de orientação pós-moderna (aquela que à medida que a tudo “dilui”, proporcionalmente também “multiplica”), considera que o ego unificado e engendrado pelo "aparelho fílmico" de Braudy não passa de uma falácia, já que no mundo contemporâneo celebrador da diversidade, só espaço para um tipo de subjetividade: a múltipla e fragmentada (cf. ALLEN; SMITH, 2005). Chama atenção, obviamente, a inexistência de qualquer tipo de formulação crítica que aponte para a maneira como esse molde da teoria de posição-subjetiva constitui-se como movimento da Teoria nos estudos de cinema. Ou seja, a teoria de posição-subjetiva, em seu encadeamento entre campos diversos como semiótica, psicanálise e o que mais convier (como as 
versões de feminismo de Mulvey e marxismo de Baudry), seu ímpeto em utilizar os filmes como elucidações e formulações e posições teóricas previamente estabelecidas, caracterizou-se de fato como um recorte, uma variação no microcosmo dos estudos de cinema, do fenômeno Teoria, discutido por Durão. Destarte, da mesma forma que, no campo da teoria literária, o advento da Teoria conferiu ao literário um estatuto incerto e dispensável, como observa Durão ${ }^{15}$, nos estudos de cinema, a dinâmica, como procuramos demonstrar, não foi diferente.

Contudo, existe no caso dessa área em particular uma contingência histórica que torna essa sujeição uma contradição, no mínimo, irônica. Se por um lado, a corrente de posição-subjetiva passou a tratar os filmes exclusivamente como índices para o exame de uma determinada estruturação psíco-social, por outro lado, foi justamente através dela que os estudos de cinema atingiram o almejado status de campo, através sua inclusão de disciplina acadêmica. Não surpreende também o fato de que isso tenha acontecido justamente no final da década de 1960, quando outro movimento que viria a se solidificar e ditar as normas na produção teórica também o encontrava-se em ascensão, os Estudos Culturais, conjurando aquilo que na observação irônica de Bordwell, configurou-se como o momento em que "uma arte de massa encontrava seu espaço na educação de massas” (p. 25). Dessa forma, a emergência da corrente culturalista, sua consolidação no meio acadêmico durante a partir de meados da década de 1980, que, com seu apelo a historicização da teoria, cambiou palavras-fetiche do vernáculo teórico como "ideologia" e "sociedade" por "cultura”, mostrou-se como uma atrativa solução para superação das limitações estruturantes da teoria de posição-subjetiva. Todavia, como ressaltam Allen e Smith, o movimento de transição entre ambas não se deu pela ruptura, mas sim por uma espécie de continuidade nas premissas doutrinárias, que findou por produzir diferentes versões da mesma corrente, cada qual com suas peculiaridades (2005, p. 71-84).

Seja como for, a influência e o interesse por aspectos culturais na teoria do cinema o não se trata de uma inovação e um sintoma exclusivo do

\footnotetext{
${ }^{15}$ Para uma discussão acerca do fenômeno da Teoria e modo como ela, em sua forma ubíqua, afeta todas as áreas da produção epistemológica, ver Durão, Giros em falso no debate da teoria (2008) e Breves observações sobre a teoria, suas contradições e o Brasil (2004).
} 
vigor da Teoria; tanto nos trabalhos de Benjamin sobre cinema quanto no interesse de Kracauer sobre o impacto do cinema na realidade social, para ficarmos apenas em dois teóricos que se detiveram sobre essa questão antes de 1960, percebe-se a relevância da dimensão cultural como eixo fundamental na discussão das transformações na experiencia social configurada pelos ditames das relações entre mercado, trabalho e capital na vida moderna. De forma análoga, o particular interesse da teoria de posição-subjetiva pelos efeitos ideológicos do cinema nos processos de identificação e construção da subjetividade, apontados nos trabalhos de Mulvey e Braudry, pode ser interpretado como uma reminiscência das investigações acerca das imbricadas relações entre cinema e realidade, características do trabalho de teóricos da teoria realista como Bazin e Kracauer. Além disso, a dimensão da cultura ocupa também um lugar de destaque nos debates acerca do pós-modernismo. Em linhas gerais, baseados na proposição de que os ditames do capital multinacional regem a vida contemporânea, resultando em uma equivalente fragmentação e achatamento da experiência, teóricos apologistas como Linda Hutcheon, por exemplo, tecem considerações acerca da capacidade do cinema, junto com as demais mídias de massa, produzir cada vez mais uma espetacularização da vida. Em contraposição, destaca-se a crítica de Jameson, tanto à forma hodierna de configuração de status da cultura quanto ao entusiasmo e perspectiva alvissareira de seus célebres teóricos.

Não obstante, a linha culturalista de maior influência na teoria do cinema, assim como nas demais áreas da produção acadêmica contemporânea é, indubitavelmente, a dos Estudos Culturais, cuja conceitualização mais geral da noção de cultura pode ser traduzida como o local de confronto de diversos grupos em certame por suas agendas específicas (cf. HALL, 1986). No que tange sua relação com o cinema, a abrangência de seu influxo é tamanha que se pode facilmente questionar se a produção teórica sobre cinema hoje existe somente por que o cinema também faz parte dos interesses da teoria cultural. Um interessante canal para se delinear tanto o impacto dos Estudos Culturais quanto a forma que ele vem caracterizando a teoria de cinema recente dá-se pelo exame dos trabalhos dos críticos norte-americanos de cinema Robert Stam e Ella Shohat, cuja prolixa produção e crítica concentram-se, sobretudo, nas representações culturais e políticas do cinema - especialmente o não 
eurocêntrico - e demais mídias, pensados a partir de uma concepção multiculturalista.

Seu volumoso livro Crítica da imagem eurocêntrica, lançado recentemente no Brasil, caracteriza-se como um amplo apanhado daquilo que é propalado como o paroxismo da "diversidade" epistemológica corrente. Para isso, propõe-se tratar "transdisciplinariamente" (uma das muitas palavrasfetiche dos Estudos Culturais) questões acerca da representação eurocêntrica em diversos campos como História, Literatura e, particularmente, Cinema e demais mídias. Em sua maior parte, o interesse central recai evidentemente em recapitular questões que, até certo ponto, elucidem explanações acerca de temas sempre muito "abertos" como multiculturalismo, pós-colonialismo e representações identitárias; sempre alertando que, por se tratarem de assuntos complexos, qualquer tentativa fechada de definição seria um anátema. Além disso, embora se façam repetidas ressalvas de que os "neoconservadores tenham caricaturado o multiculturalismo como uma rejeição dos clássicos europeus", a crítica aqui não se dirige à Europa, mas sim, a um abstrato eurocentrismo, redutor da diversidade cultural a uma perspectiva paradigmática da Europa como o único ponto de produção de significados; uma espécie de “centro de gravidade do mundo, como 'realidade' ontológica em comparação com a sombra do resto do mundo" (p. 20). A linha argumentativa segue análoga ao raciocínio empregado por Said na epitomada obra dos Estudos Culturais, Orientalismo: oriente como invenção do ocidente (2003), acerca das estratégias e formas representativas sob as quais o ocidente erigiu representações identitárias tanto do "outro", não europeu, em especial o ocidental, quanto de si mesmo. No que tange a relação entre forma e conteúdo, chama atenção à maneira como que, para os autores, a temática da abundância, diversidade e fragmentação, vociferadas ad nauseam no argumento central, constituem-se também como elementos de estruturação retórica do texto; assim, a extensa enumeração de um extenso escopo de filmes, outros tipos de vídeos, documentários, e congêneres, são jogados desregradamente na mélange do grande melting pot; como se uma apurada discussão acerca da "multiplicidade racial", por exemplo, não devesse em absoluto prescindir de mencionar uma listagem de títulos. Este, aliás, é um dos traços marcante na forma de abordagem de filmes entre os escritos da teoria de posição-subjetiva 
e do culturalismo; neste último, instaura-se uma tendência de "abordagem de repertório", onde uma proposição é exemplificada com a enumeração com uma dezena de títulos ${ }^{16}$. Da mesma maneira, o cruzamento, ou interconexões, como eles preferem chamar, das variadas referências culturais e geopolíticas, não oblitera o fato de que o latente empenho em rompimento com linearidade espaço-temporal tenciona criar uma sensação de complexidade e resistência à totalidade, numa espécie de virtuosismo retórico, não passa de uma falácia argumentativa ${ }^{17}$.

Todavia, dentre os problemas apontados, o mais intrigante certamente refere-se à própria temática geradora do livro. Mais de cinco décadas após início da crítica pós-colonial (e sua literatura correspondente), o lançamento de um extenso livro ${ }^{18}$, cuja temática busca traçar uma genealogia de como o repertório de representações (seja no registro escrito ou visual) engendrado pelo chamado discurso eurocêntrico forjou imagens e estereótipos identitários, não representa nenhuma novidade, seja ao debate dos Estudos Culturais, ou mesmo à teoria de cinema, visto que, desde o inflamado, e hoje canônico ensaio de nigeriano Chinua Achebe, "An image of Africa: racism in Conrad's Heart of Darkness" (1973), alertou o mundo sobre as imprecisões e estereótipos nas formas de representação do "outro" erigidas pelo cânone ocidental, abriu-se as comportas para uma torrente de "respostas", "romances de releitura e rescrita", e toda sorte de produção anti-cânone da qual emanou o gênero pós-colonial.

Diante do exposto, não há como não pensar um livro como este, como a sintomática expressão de mercado editorial que encontrou na máquina acadêmica norte-americana de produção de artigos, livros e congressos, um nicho com possibilidades múltiplas e inesgotáveis de lucros. É justamente dentro dessa conjuntura que o livro de Shohat e Stam explica sua razão de ser: mais do mesmo, uma variação sobre o mesmo tema dos Estudos Culturais, ou

\footnotetext{
${ }^{16}$ Esse modus operandi domina quase todo o livro, mas destacaria os capítulos "Etnicidades-em-relação" (p. 313-353) e "O cinema terceiro-mundista" (p. 355-405).

${ }^{17}$ Ver a excelente crítica que Durão faz o estilo obscurantista de escrita de Gayatri Spivak que, entre outras coisas, resvala num "narcisismo patente" e numa assoberbada valorização do "eu". Em DURÃO, Da politização da desconstrução em Gayatri Spivak, 2009, p. 296.

${ }^{18}$ São oito capítulos distribuídos em mais de quinhentas páginas.
} 
para ser mais explícito, um livro que procura apenas ilustrar ${ }^{19}$ através de sua abundante referência a filmes e outras produções midiáticas o argumento de Said em Orientalismo sobre o processo de construção da alteridade. Difícil é não sentir o sabor de algo requentado e não perceber, mais uma vez, o empenho e o anseio em ter uma proposição teórica aplicada e comprovada.

Já a posição de Shohat e Stam quanto ao status da teoria do cinema na atualidade fica exposta no ensaio "Teoria do cinema e espectatorialidade na era dos 'Pós'”, que encerra a o primeiro volume da coletânea coligida por Ramos, ou ainda, no capítulo final de Introdução à teoria do cinema, de Stam, intitulado "Pós-cinema: a teoria digital e novos meios". Nesses dois textos, advoga-se que o desenvolvimento das tecnologias audiovisuais representa um dramático sobre praticamente todas as questões elaboradas pela teoria do cinema e, embora muitos vaticinem de forma apocalíptica o fim do cinema e a improdutividade de qualquer tentativa de elaboração teórica, a situação de ambos (cinema e teoria) assemelha-se muito os primórdios do surgimento do cinema como meio. Ou seja, o reconhecimento de sua crise enquanto campo teórico autônomo pode ser entendido como a possibilidade de um novo recomeço, repleto de possibilidades. Nesse tom alvissareiro, ambos avaliam que a conjuntura de um mundo onde a cultura encontra-se amplamente internacionalizada, uma teorização sobre o cinema não pode/deve se confinar em molduras totalizantes. Nessa linha, seguem as mais estapafúrdias e equivocadas asserções como: a mesma globalização que dissemina e impõe conteúdos culturais, produz paradoxalmente pontos de resistência, uma vez que a falência do conceito de identidade vinculada às nações possibilita a formação de alteridades em comunidades desvinculadas de espaços territoriais ou regimes políticos.

Por fim, penso ser salutar encerar essa discussão tecendo algumas considerações acerca da forma como configuração da teoria contemporânea do cinema penetra no Brasil e afeta de maneira incisiva a modesta e parca

\footnotetext{
${ }^{19}$ Uma posição mais radical classificaria esse a motivação para um livro como esse, no mínimo, como oportunista.
} 
produção crítica de cinema ${ }^{20}$. O "A alegoria histórica", de Ismail Xavier, certamente o nome mais proeminente nome da crítica de cinema brasileiro, reflete inequivocamente a força e influência dos Estudos Culturais, traduzida numa espécie de sintonia com essa forma de crítica e que corrobora a máxima acerca da tradição dos círculos acadêmicos brasileiros como importadores e ávidos consumidores de formulações teóricas anglo/francofônicas. Era de se esperar que, justamente pela sua posição de crítico alocado em um país com tradição de aplicação de teorias, Xavier pudesse apontar os problemas, equívocos e falácias de uma teorização que elegeu noções frouxas como pluralidade, diversidade, diferença como única via paradigmática. Contrário a isso, o crítico brasileiro filia-se justamente ao conceito "pós-colonial" e suas estratégias de resistência, tão caras aos Estudos Culturais, para argumentar que a produção cinematográfica contemporânea (hispano-americana e brasileira), cada vez mais, vem valendo-se "estrategicamente" do esgotamento e fragmentação da categoria de alegoria na reelaboração do conceito de nação. Ora, surpreende tal asserção quando se testemunha o movimento contrário: filmes centrados em temáticas como diversidade, resistência, biografia de mártires, violência, pobreza e injustiça social ${ }^{21}$ vêm, cada vez, tornando-se grandes sucessos bilheterias advogam ainda pelo endêmico potencial de resistência do "cinema pós-colonial", caracterizado por movimentos estéticos de contra-cinema com alguma expressão entres décadas de 1960-70 como o Movimento do Cinema Novo, no Brasil, os filmes latino-americanos produzidos sob a influência do manifesto "Cinema Imperfeito" do cubano Julio Garcia Espinosa (1969).

\footnotetext{
${ }^{20} \mathrm{~A}$ penetração e forma como os Estudos Culturais vêm ditando os paradigmas na produção de crítica de cinema no cenário acadêmico brasileiro constitui, certamente, uma fecunda matéria para reflexão que o espaço deste trabalho não abarcar. Mas é, sem dúvidas, uma questão a ser debatida.

${ }^{21}$ Diversidade e tolerância sexual: Transamérica (2006); exploração de nações africanas: $O$ jardineiro fiel (2006); Diamante de sangue (2007); ditadores e guerra civil na África: Hotel Ruanda (2004), O último rei da Escócia (2006); oriente médio: Persépolis (2007); biografia de mártires: Diários de motocicletas (2004), Che (2009); violência, pobreza e injustiça social: Cidade de deus (2002), Quem quer ser um milionário (2008).
} 


\section{Referências}

ACHEBE, C. An image of Africa: racism in Conrad's heart of darkness. In: LEITCH, V. (Org.). The norton anthology of theory and criticism. 2001, p. 17831794.

ALLEN, R; SMITH, M. Teoria do cinema e filosofia. In: RAMOS, F. (Org.). Teoria contemporânea do cinema: pós-estruturalismo e filosofia analítica. Trad. Fernando Mascarello. São Paulo: Senac, 2005, p. 71-112.

ANDREW, J. D. As principais teorias do cinema: uma introdução. Trad. Tereza Ottoni. Rio de Janeiro: J. Zahar, 2002.

BAUDRY, J. L. Cinema: efeitos ideológicos produzidos pelo aparelho de base. Trad. Vinícius Dantas. In: Xavier. I (Org.). A experiência do cinema. 3. ed. Rio de Janeiro: Graal, 2003, p. 383-399.

BORDWELL, D. Estudos de cinema hoje e as vicissitudes da grande teoria. In Ramos (Org.). Teoria contemporânea do cinema: pós-estruturalismo e filosofia analítica. Trad. Fernando Mascarello. São Paulo: Senac, 2005, p. 25-70.

BORDWELL, D.; STAIGER, J. THOMPSON, K. The classical hollywood cinema. New York: Columbia University Press, 1985.

DURÃO, F. Giros em falso no debate da teoria, v. 10. Rio de Janeiro: Estudos Neolatinos, 2008, p. 54-69.

DURÃO, F. Breves observações sobre a teoria, suas contradições e o Brasil. Revista de Letras, v. 44, n. 1. São Paulo: 2004, p. 81-95.

DURÃO, F. Da politização da desconstrução em Gayatri Spivak. Revista de Letras, v. 49, n. 2. São Paulo: 2009, p. 289-301.

EISENSTEIN, S. A forma do filme. Trad. Tereza Ottoni. Rio de Janeiro: J. Zahar, 1990.

GLEDHILL, C. Home is where the heart is: studies in melodrama and the woman's film. Londres: British Film Institute, 1987.

HALL, S. Cultural studies: two paradigms. In: COLLINS, R. Media, culture, and society: a critical reader. Londres: Sage, 1996, p. 32-45.

KRACAUER, S. From caligary to Hitler: a psychological history of the german film. Trad. Leonardo Quaresima. Princeton University Press, 2004. 
KUHN, A. Women's picutures: feminism and cinema. Londres: Routledge, 1982.

METZ, C. A significação no cinema. Trad. Jean-Claude Bernardet. 2. ed. São Paulo: Perspetiva, 2007.

METZ, C. Linguagem e cinema. Trad. Marilda Pereira. São Paulo: Perspetiva, 1980.

METZ, C. The imaginary signifier: psychoanalysis and the cinema. Trad. Celia Britton. Bloomington, 1982.

MULVEY, L. Prazer visual e cinema narrativo. Trad. João Luiz Vieira. In: XAVIER, I. (Org.). A experiência do cinema. 3. ed. Rio de Janeiro: Graal, 2003, p. 437-453.

MULVEY, L. Reflexões sobre "Prazer visual e cinema narrativo" inspiradas por Duelo ao Sol, de King Vidor (1946). Trad. Silvana Vieira. In: RAMOS, F. P. (Org.). Teoria contemporânea do cinema: pós-estruturalismo e filosofia analítica, v. 1 . São Paulo: Senac, 2005, p. 381-392.

RAMOS, F. P. Teoria contemporânea do cinema: pós-estruturalismo e filosofia analítica, v. 1. São Paulo: Senac, 2005.

RAMOS, F. P. Teoria contemporânea do cinema: documentário e narratividade ficcional, v. 2. São Paulo: Senac, 2005.

SAID, E. Orientalismo: o oriente como invenção do ocidente. Trad. Rosaura Eichenberg. São Paulo: Cia das Letras, 2007.

STAM, R. Introdução à teoria do cinema. 2. ed. Trad. Fernando Mascarello. Campinas: Papirus, 2006.

SHOHAT, E; STAM, R. Crítica da imagem eurocêntrica. Trad. Marcos Soares. São Paulo: Cosac Naify, 2006.

SHOHAT, E; STAM, R. Teoria do cinema e espectatorialidade na era dos "pós". Trad. Fernando Mascarello. In: RAMOS, F. P. (Org.). Teoria contemporânea do cinema: pós-estruturalismo e filosofia analítica, v. I. São Paulo: Senac, 2005, p. $381-424$

TURNER, G. Cinema como prática social. Trad. Mauro Silva. São Paulo: Summus, 1997.

XAVIER. I. A experiência do cinema. 3. ed. Rio de Janeiro: Graal, 2003. 
A TEORIA CONTEMPORÂNEA DO CINEMA

XAVIER. I. A alegoria histórica. In: RAMOS, F. P (Org.). Teoria contemporânea do cinema: pós-estruturalismo e filosofia analítica, v. 1. São Paulo: Senac, 2005, p. 339-379.

Recebido em 15 de julho de 2016

Aceito em 8 de agosto de 2016 
